\title{
The Factors that Influence in Human Resources Management at the Clinical Hospital in
} Tetovo

\author{
Valdrina Fetai \\ Faculty of Medical Sciences of the University of Tetova, Republic of Macedonia \\ Naxhije Fetai \\ Surgical Department, Clinical Hospital of Tetovo, Republic of Macedonia
}

\begin{abstract}
Human Resource Management within healthcare institutions is an important part of their organization and as such, it is quite complicated, complex and dynamic. The interest in managing with human resources is crucial all around the world, since the success of daily activities as well as the welfare of the functioning of healthcare centers largely depend on the mode of human resource management within those institutions. The aim of this paper is to analyze the factors that influence in successfulness and efficiency of human resource management at the Clinical Hospital in Tetovo which in turn directly influences the improvement of the quality of medical services provided by the medical staff and to analyze the organizational structure at this public healthcare institution. During the first quarter of 2018 interviews with employees in some of the wards of this hospital were done related to their daily activities, services they provide, problems and challenges they face. Also, the level of satisfaction from the assessment of their work by the institution has been measured. Some of the major problems that were emphasized in all of the groups of interviewees had to deal with low salaries and the lack of additional compensations that can significantly motivate them in the more successful realization of their daily duties and activities. The stimulation and motivation of the medical staff for professional development and continuous education through various different professional development workshops, seminars, conferences, symposiums, etc. has a great impact on the overall performance of the employees. The adequate equipment of wards with the most modern items and devices is more than crucial for a smooth realization of daily activities and it also has a direct impact on the achieved results. Successes and achievements in the field of medicine are closely related to the scientific advancements in general. Healthcare institutions at all levels should treat their personnel better by providing them more reasonable salaries and rewards for their good performance as well as additional financial support for their further professional development. Competent bodies within the Ministry of Healthcare should actively monitor the quality of provided healthcare services by the medical personnel, encourage, and invest in their efficient distribution and dissemination.
\end{abstract}

Keywords: organizational structures within healthcare institutions, human resource management, leadership, motivation, quality assurance and professionalism

\section{Introduction}

Human Resource Management within healthcare institutions is an important part of their organization and as such is quite complicated, complex and dynamic. The interest in managing with human resources is crucial all around the world, since the success of daily activities as well as the welfare of the functioning of healthcare centers largely depend on the mode of human resource management within those institutions.

Parallel experiences clearly show that traditional leadership patterns, which appear as inflexible forms, now lose the importance of functioning and are largely replaced with more contemporary and sophisticated leadership models, more flexible, humanistic and more practical models, namely the contemporary management of human resources.

The health system in general, guided by this system and its development, is increasingly attracting the attention of society. Prior to the institutional leaders there's a great challenge to understand in a transparent way the world we live in today and be able to contemplate the future and the possible changes in it. 
Today, with the new legal decisions in the health institutions, the decision to run with two directors should be implemented. This increasingly strengthens the need for comprehensive implementation of health management and all this is accomplished through an adequate organizational structure of the health system in general, which is of paramount importance in the health care of patients through the provision of great quality to the health services.

These changes, however, should be added to the beginning of the health system transformation process and privatization in the health sector, which implies change in several levels and in many segments of the overall health system. The primary goal of this process is to improve the quality of health services, one of which is the increase of the satisfaction of the users of these services, while the ultimate goal is to provide a more efficient, accessible, social and solid health system for all, which will work at estimated and controlled costs. All this means greater responsibility of health institutions and medical personnel in achieving institutional goals and in achieving high professional performance.

\section{Aim}

The health system is considered to be one of the most complex systems in society; therefore, its successful functioning represents a great and necessary need. The aim of this paper is to analyze the factors that influence the successfulness and efficiency of human resource management at Clinical Hospital in Tetovo, which directly influences the improvement of the quality of medical services provided by medical staff and to analyze the organizational structure of this public healthcare institution.

Through the given health indicators to define the existing situation and then consider the possibility of drafting an adequate health policy with the preparation of certain plans, programs and activities that should be implemented through appropriate decisions both in the institution concerned and in the system health as a whole.

\section{Methodology}

The subject of this paper was the assessment of the success of the daily activities of the medical staff of some departments at the Clinical Hospital of Tetovo. During the first quarter of 2018, interviews with employees in some of the wards of this hospital were made related to their daily activities, services they provide, problems and challenges they face. Also, the level of satisfaction with the assessment of their work by the institution has been measured, the level and difficulties they face in their work either as a result of the lack of equipment and equipment or the materials and tools necessary for realization of their activity with success.

\section{Results}

This study was conducted in seven departments of the Tetovo Clinical Hospital:

Surgical Department;

Urology Department;

Orthopedic Department;

Gynecological - Obstetrics Department;

Internistic Department of Internal Diseases;

Pediatric and

Neurological Department.

Personnel employed in these units as specialist doctors, secondary doctors, nurses as well as auxiliary and sanitary personnel were interviewed through questionnaires prepared in advance. Responses given by employees clearly show that one of the major problems in all of the abovementioned groups is the low wage but also the absence of additional compensation such as bonuses, awards or acknowledgments that have a significant impact on their motivation for achieving as much most successful daytime activities.

Lack of stimulation and promotion of medical staff for professional upgrading and continuous education, which is accomplished through the pursuit of training courses, symposiums, congresses or scientific conferences, is also another element that has a significant impact on the professional preparation and with this also in the successes shown at work. 
The adequate equipment of the aforementioned units with the modern equipment and instruments necessary for the realization of daily activities, which in most cases is far from optimal, is also another factor which hampers the work of the medical staff and has a direct impact on the achieved results.

According to the study conducted and analyzes made - a very important factor that affects the successful management of human resources is also the character of the leader. As a matter of fact, a good leader must possess professional qualities such as self-confidence, sustainability, professionalism, communication skills and loyalty to the work and the staff employed, for the purpose of successful realization of his leadership activity.

\section{Conclusions}

The human factor should be accounted for as one of the most important health care links.

Managers of health institutions at all levels should treat the medical staff as best as possible by offering them not only reasonable wages but at the same time motivating them with bonuses, awards or acknowledgments for any good result in their work that differentiates from that of other colleagues.

The establishment of a long-term national strategy for human resource management in healthcare institutions and the provision of financial means necessary for the permanent advancement of medical staff in certain directions remains a factor of particular importance for the quality and success of medical services.

Competent bodies within the Ministry of Health or hospital departments should actively monitor the quality of services provided by the medical staff and promote and invest in the effective distribution of this staff. They should also build flexible and appropriate organizational structures for dynamic and complex environmental changes.

Harmonization of medical services across the country is of special importance and necessary for the success of the health institution.

Taking into account the daily activities of the institutional manager, it is required to be more innovative, more flexible, to respect the knowledge and experience of employees at all levels of the institution, to advance teamwork, to advance communication between departments and units and reward the employees for the quality work accomplished.

The principle of equality and justice must be enforced by the medical staff during the provision of health services, which is carried out in such a way that each citizen, depending on the form and the character of his medical requirements, can simultaneously fulfill his health requirements. First and foremost, it is about the published transparent waiting lists.

Successes in the field of medicine are closely and directly related to the pursuit of achievements in science. Therefore, with the change of the system of the undergraduate education of medical staff and its harmonization with the system that dominates in the European Union, especially with the postulate that the healthcare professional has an obligation to permanently acquire new information, skills and knowledge; to be allowed to be supplied with newest tools (most modern medical technology); adaptation and functional health area and a reasonable and effective human resource policy that enables greater efficiency; in the future it will be necessary to gradually harmonize the way of realization and verification of the specialization, so that it is identical to the one proposed by the European health associations, i.e. it should be harmonized with those currently implemented in the European Union.

It should be ensured that all healthcare activities are carried out in all areas where the health service and medical activities are applied, in a qualitative atmosphere and manner, ranging from the way patients behave (applying all national and international rules the rights of patients that are in effect) to the application of internal rules in the performance of workplace duties at health centers and institutions.

Taking into account the nature of the work in health institutions, healthcare as an activity is often counted as a place where, due to negligence and professional failure, there often occur health damages, loss of patient life or loss of life medical personnel. That is why it is mandatory to establish legal rules for adequate medical devices according to the examples of member countries in the European Union. The greatest deviation from the normal functioning of the individual in the collective and his inability to perform daily tasks occurs during the loss of health or injury. These situations in most cases are the reasons for the greatest number of other consequences (financial problems, inability to work, need for help from others). Every activity, event, segment of the process and the outcomes that have to do with the health condition should still be recorded. 
On the other hand, taking into account the rules in contemporary medicine, due to the possible digitization of all these phenomena, not only must they be recorded, but they must be adequately memorized but always be at the disposal of those who are authorized to make certain decisions, ranging from decision-making health bodies that define rules, concepts, follow up the realization and carry out the ongoing supervision of the activity; to medical personnel who must necessarily be informed of any work done for the patient, in any segment of the patient's healthcare system, which is subject to attention and care; and to the insurance institutions who justify and take over all the health insurance costs. Today, with the rapid development of computer technology, it is wise to immediately (on-line) access all data and cases related to all therapeutic interventions.

Good and continuous communication between staff at all levels of the health system and especially the division of work between them, governed and managed fairly, will enable the successful functioning of all parts of the levels of this system.

\section{Literature}

[1] Flunn W, Mathis R, Jackson J, Langan P. Healthcare Human Resource Management. Mason, OH: Thomas South - Western; 2004

[2] Law on Health of the Republic of Macedonia.

[3] Law on Protection of Patients' Rights in the Republic of Macedonia.

[4] Leiyu Shi, Jones and Bartlett Publishers, Managing human resources in healthcare organizations, Inc., Ontario, Canada, 2007;157-185.

[5] Public Health Law of the Republic of Macedonia.

[6] Robey Daniel. Designing organizations, Third edition IRWIN. Burr Ridge, Illinois, 1991.

[7] Sherman Folland, Allen Goodman, Miron Stano. Economics of Health and Health Care, 2008.

[8] Termino, E \& Webster, E.G., Primary Health Concepts and challenges in a changing world: Altna - Ata revisited. Geneva, World Health Organization. 1997

[9] World Health Organization, Transition Health Report, 2000, Reforms in the Health System in Macedonia, www.crpm.org.mk

[10] Zeqiri I., The Management. Tetovo 2006. 